\title{
POWER QUALITY MEASUREMENT CAPABILITIES OF "SMART" ENERGY METERS
}

\author{
T. Solvang ${ }^{1}$, L. Aleixo ${ }^{1}$ and H. Seljeseth ${ }^{1}$ \\ ${ }^{1}$ SINTEF Energy Research \\ N-7465 Trondheim (Norway) \\ Phone number: 004773537200 \\ Fax number: 004773537250 \\ e-mail: tarjei.solvang@ sintef.no, luis.aleixo@sintef.no, helge.seljeseth@sintef.no
}

\begin{abstract}
Power quality measurement integrated in energy meters are presented as a potential benefit by some manufacturers. The Norwegian regulator has considered making minimum requirements for energy meters to include registration of interruptions. SINTEF Energy Research has performed tests on energy meters with power quality measurement capabilities. These tests include the ability to detect interruptions, supply voltage variations, voltage dips, among others. Results presented in this paper show large differences in capabilities for power quality measurement of 'smart' energy meters. The results also show that the power quality measurements are not according to international standards for such measurements like EN50160 [1], IEC 61000-4-30 [2] and others.
\end{abstract}

\section{Key words}

Power Quality, Power Quality Measurement, Power Quality Standards, Energy Meters, Meter Testing

\section{Introduction}

Power quality is one of the main issues in today's electrical market. While some years ago, utilities main concern was mainly to deliver the energy required by the customers, it is today required that such energy fulfils quality standards that ensures the necessary safety and reliability to guarantee the consumers' equipment protection and safety.

With the increased relevance of power quality in the electrical system (especially to consumers), having equipment able to measure power quality as well as energy became significantly important because it can provide the real-time information necessary to prevent problems in the installed equipment [3] [4] [5]. By including power quality technology, it is possible to make use of the latest advancements in ICT already established in energy metering and take advantage of their low costs.

The Norwegian Regulator (NVE) is currently working on a new regulation regarding energy measurement. In the draft for this regulation, voltage quality measurement is not mentioned yet as a mandatory functionality. The registration of interruptions is however mandatory. Based on statements from vendors claiming that energy meters will not be able to register interruptions according to power quality standards such as the EN50160 [1], the Norwegian regulator has suggested a requirement that the meters should register an event when the voltage falls below $115 \mathrm{~V}$ (50\% of $\left.\mathrm{U}_{\text {Nominal }}\right)$. The time stamp should have an accuracy of minimum 1 second. [6]

Today's market presents already many solutions of 'smart' meters capable of providing both the services given by 'old' meters and power quality related measurements. However, detailed documentation of the 'smart' meters abilities in this last field are seldom given by manufacturers. This makes it difficult to understand 
how well developed these 'smart' meters are in the power quality measurement area and which one is more suited for each customer purpose. [7] In fact, SINTEF Energy Research previous investigations on specialised power quality measurement equipment have even shown that even specialized equipment for power quality measurement from different manufacturers present quite different measurement results, in particular for flicker.

Currently, SINTEF Energy Research has a five year project (started on 2007) to develop a new concept for power quality and reliability measurement and management, the PQM project (project website: http://www.energy.sintef.no/prosjekt/PQM/) where "smart" meters are tested in order to assess and describe their abilities and performances regarding power quality metering.

\section{Objectives and prerequisites}

SINTEF Energy Research has tested five energy meters from four different vendors. The meters have different levels of power quality measurement capabilities. The objective of these tests was to investigate the capability and quality of the meters in terms of power quality measurements and to see how energy meters with power quality measurement capabilities can be used in a large scale. SINTEF Energy Research has focused on testing meters that are on the market today and not on what the different vendors claim they can deliver in the future.

SINTEF Energy Research has prioritised to test energy meters from vendors already present in the Nordic market. These vendors are also present in the international market.

The choice and quality of software solutions, communications technologies and data formats are not included in this evaluation. The price of the different meters is also disregarded although the price in Norway for some of these meters range from approx. $€ 25$ to 40 .

The objective of these tests is not rank energy meters from different vendors and the names of the participating vendors are therefore made anonymous.

\section{Meter and test description}

\section{A. General}

A description of the functionalities of the investigated energy meters is presented in Table 1 . The same capital letter in the meter name indicates that the meters are provided by the same vendor.

The energy meters were tested against what they claim to measure. This means that several power quality phenomena were omitted from the tests since none of the tested meters could measure them. The tests focused on the following phenomena:
- Accuracy of voltage measurement

- Registrations of supply voltage variations

- Registrations of interruptions

- Lowest functional voltage

- Registrations of voltage dips

Lowest functional voltage means the voltage level at which the energy meter ceases to function. For meter D1, only registration of interruptions and test of lowest functional voltage is applicable since the meter did not register voltage.

Table 1: Meter description

\begin{tabular}{|c|c|c|c|c|c|}
\hline & \multicolumn{5}{|c|}{ Meter } \\
\cline { 2 - 6 } & A1 & B1 & B2 & C1 & D1 \\
\hline Category $^{1}$ & 1 & 1 & 2 & 1 & 1 \\
\hline Phases & 3 & 3 & 3 & 1 & 3 \\
\hline Voltage measurement $^{2}$ & Yes & Yes & Yes & Yes & No \\
\hline Current measurement & Yes & Yes & Yes & Yes & No \\
\hline Frequency measurement & No & Yes & Yes & Yes & No \\
\hline Unbalance measurement & No & No & Yes & No & No \\
\hline Registration of interruptions & Yes & Yes & Yes & Yes & Yes \\
\hline Predefined event registration & Yes & Yes & Yes & No & No \\
\hline Programmable events & No & No & Yes & No & No \\
\hline
\end{tabular}

The measurement results from the different energy meters were obtained through software provided by the meter manufacturers. Table 1 presents the functionalities available in each meter's software. It is therefore possible that other functionality could be obtained through software changes or updates.

\section{B. $\quad$ Test procedures}

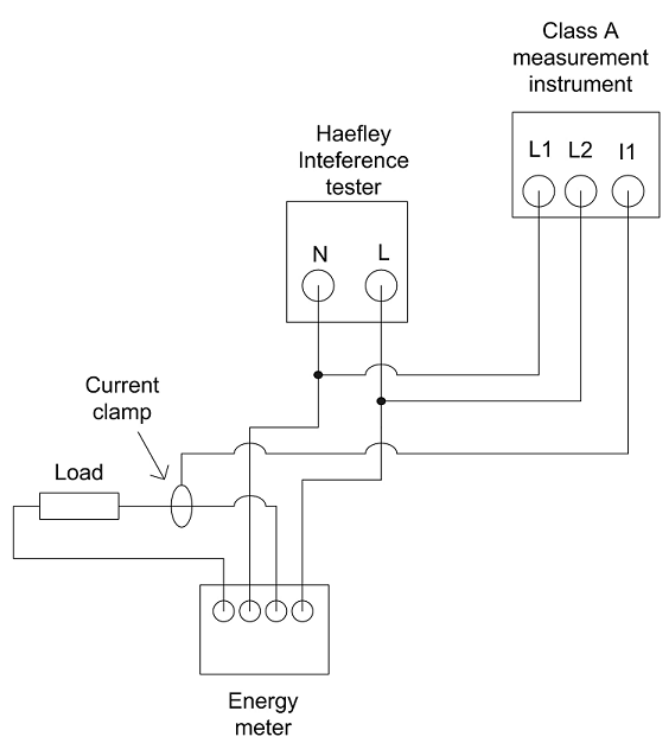

Figure 1: Test circuit

1 - Category 1 = Household, Category 2 = Commercial 
The tests were performed by applying a controlled onephase voltage signal to the energy meters by using a voltage generator. A Class A power quality measurement instrument (according to IEC standard 6100-4-30 [2]) was connected in parallel with the energy meter in order to verify the signal provided by the voltage generator and results given by the energy meters.

The test circuit established to evaluate the power quality capabilities of the different energy meters is shown in Figure 1.

The measurement accuracy was tested by comparing the voltage reading from the energy meter up against the reading from the Class A measurement instrument.

Registrations of supply voltage variations were tested by changing the voltage supplied by the voltage generator between different stationary levels and evaluate the registrations in the energy meters.

The energy meters ability to register interruptions was evaluated by exposing the meters to low voltages and see at which voltage level the meters reported that an interruption had occurred. The lowest tolerance voltage was found by investigating at which voltage level the energy meters ceases to function due to lack of power.

How the duration of the different phenomena described above affected the registrations was investigated for all tests.

The meters ability to register voltage dips was investigated by exposing the meters to dips at different depths and durations.

\section{Results}

The test results for the different energy meters are shown in Figures 2 to 6 . The blue coloured areas are where the meters report an "undervoltage" event and the yellow areas are when the meters report an interruption. The red areas are areas where the response from the meters is undetermined due to limitations in the voltage generator. A comparison of the measurement results for the different meters up against the definitions in EN50160 has been made and is shown in the same figures. The definition of voltage dips, interruptions and under voltages is shown as different patterns according to the EN50160.

The responses from meter A1 is given in Figure 2. The following should be noted. Voltage dips and interruptions with duration of 1 second or shorter are not registered by the meter. The voltage level for when the meter registers an interruption is $48 \%$, this equal to the lowest functional voltage for the meter. In addition undervoltages are only registered if the duration is longer than 10 seconds and the applied voltage is below the specified threshold ( $90 \%$ of $\mathrm{U}_{\text {Nominal }}$ ) during the entire 10 second period.

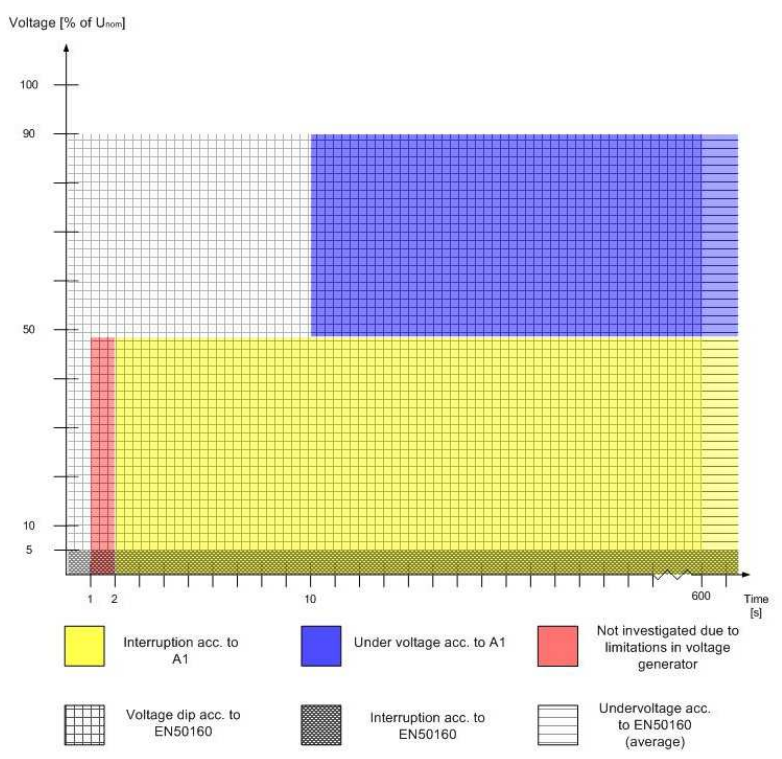

Figure 2: Test results Meter A1 compared to EN50160

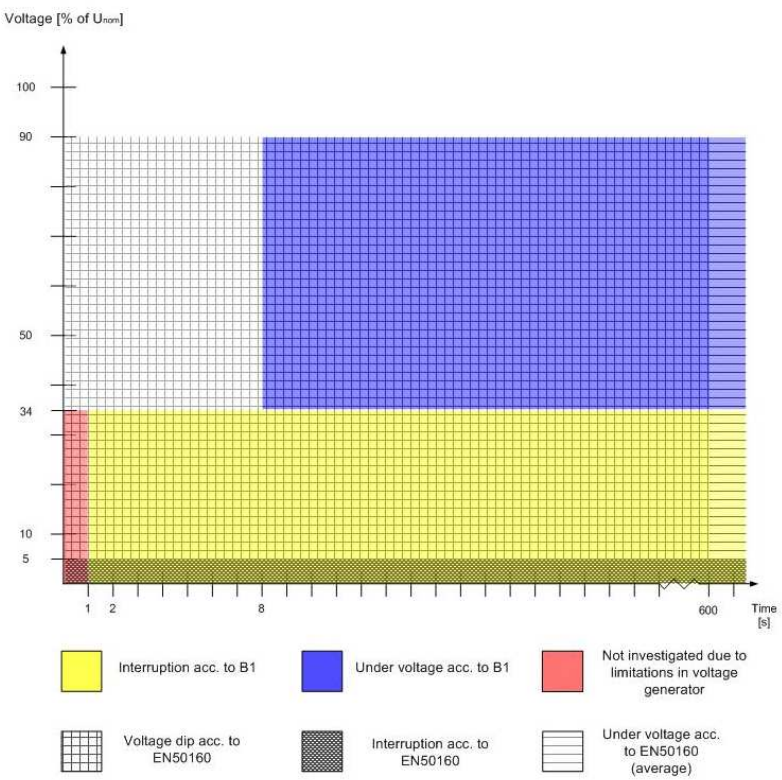

Figure 3: Test results Meter B1 compared to EN50160

Meter B1 registers all disturbances with duration of more than 1 second and a minimum voltage below $34 \%$ of $\mathrm{U}_{\text {Nominal }}$ as interruptions. Disturbances with a higher minimum voltage and duration less than 8 seconds are not registered by the meter. To register an undervoltage it must be exposed to a disturbance with a minimum voltage between $90 \%$ and $34 \%$ of $\mathrm{U}_{\text {Nominal }}$. This is shown in Figure 3. As with meter A1, the voltage must be below the specified threshold for undervoltages during the entire duration of the disturbance to be registered.

The lowest functional voltage for this meter is also the same as the threshold for registrations of interruptions.

Meter B2 reported that an interruption has occurred when exposed to a disturbance with minimum voltage of less than $14 \%$ of $\mathrm{U}_{\text {Nominal }}$ and duration of more than 9 seconds. If the duration was less than 4 seconds, every 
disturbance with a minimum voltage less than $10 \%$ of $\mathrm{U}_{\text {Nominal }}$ was reported as an interruption. Between 4 and 9 seconds the meter reported various results between tests (both interruptions and under voltages was reported. This is indicated by the purple area in Figure 4. Disturbances with minimum voltage between $90 \%$ and $14 \%$ of $U_{\text {Nominal }}$ and duration of more than 4 seconds are always reported as under voltages as long as the voltage stays between these levels during the entire interval.

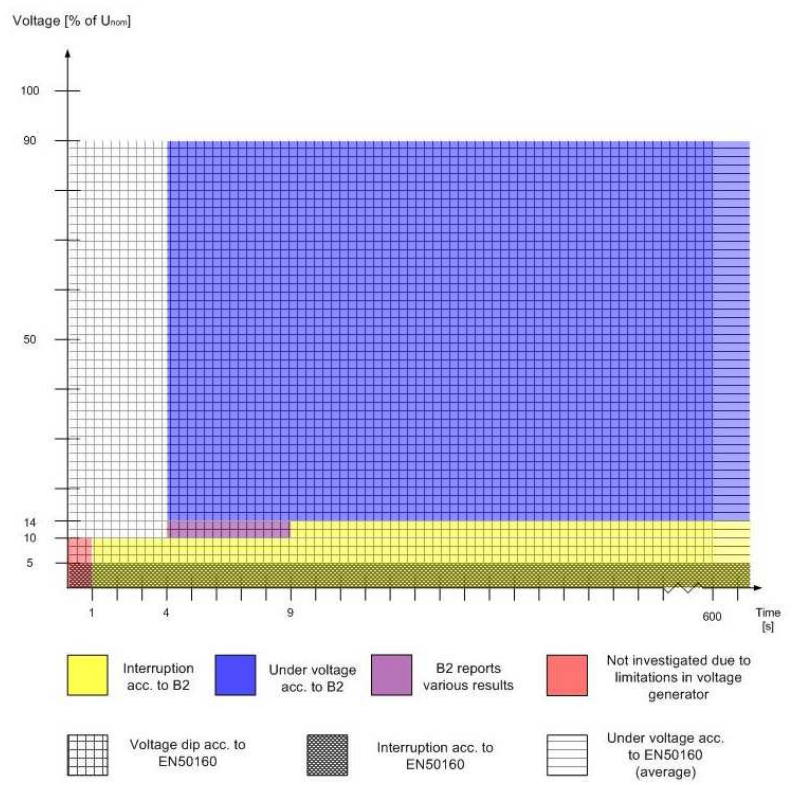

Figure 4: Test results Meter B2 compared to EN50160

The lowest functional voltage for meter B2 is the same as the voltage level for registrations of interruptions.

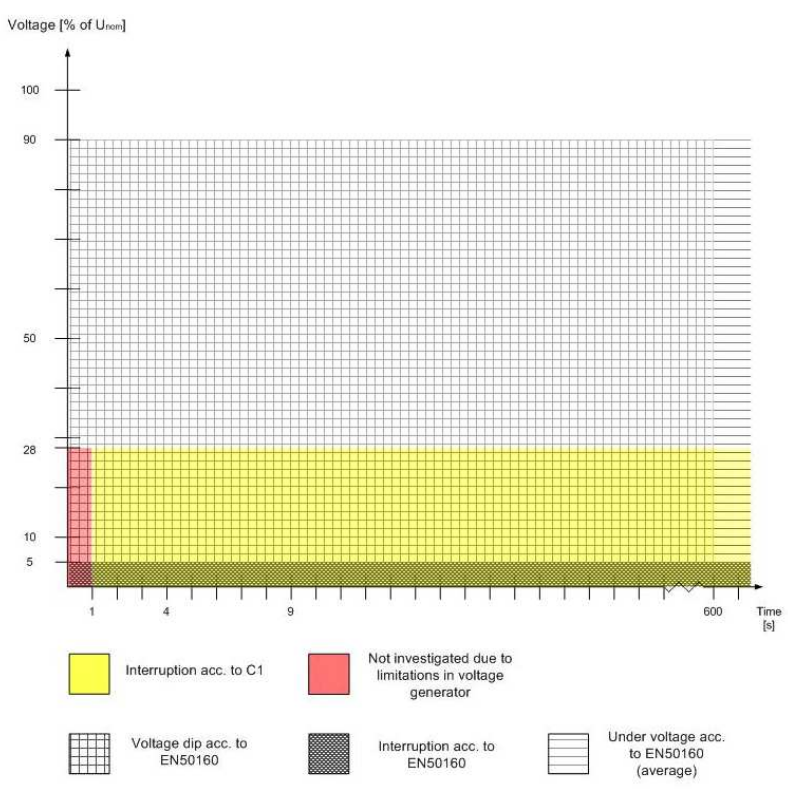

Figure 5: Test results Meter C1 compared to EN50160

Meter C1 has no functionality for registration of events other than interruptions. However, this is the only meter which measures the voltage as 10-minute averages according to EN50160 instead of momentary values. This meter will register all disturbances with minimum voltage less than $28 \%$ of $\mathrm{U}_{\text {Nominal }}$ and duration of more than 1 second as interruptions. $28 \%$ of $\mathrm{U}_{\text {Nominal }}$ is also the lowest functional voltage.

The only power quality ability included in meter D1 is registration of interruptions. For disturbances with minimum voltage of less than $68 \%$ and duration longer than 1 second the meter will report that an interruption has occurred. However, it should be noted that the lowest functional voltage of this meter is $24 \%$.

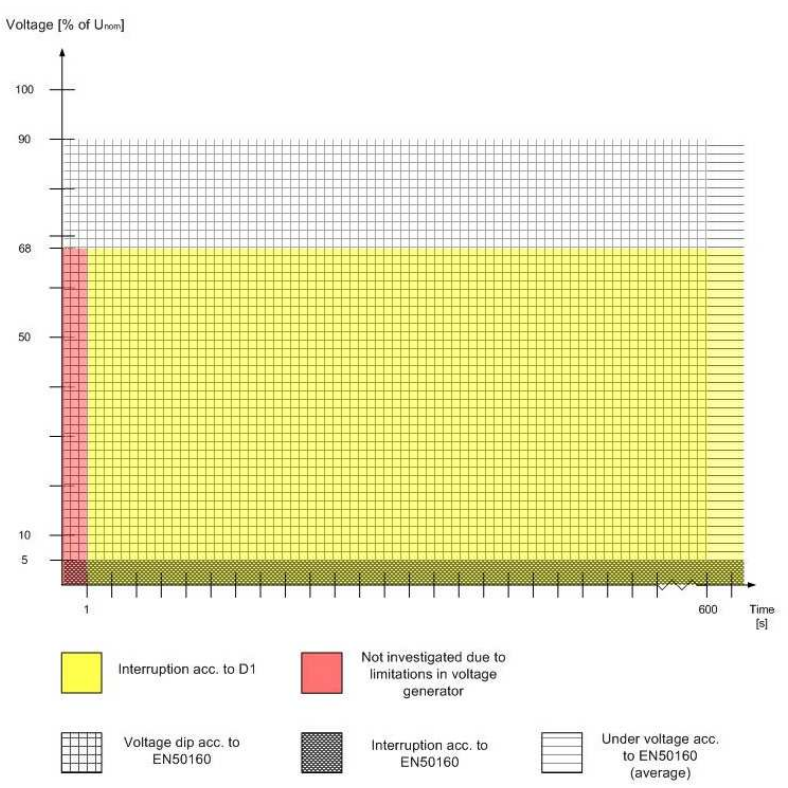

Figure 6: Test results Meter D1 compared to EN50160

Table 2 presents comparable test results from the performed tests. It shows that the measurement accuracy for stationary voltage varies between $0.1 \%$ and $0.5 \%$ of nominal voltage. It also shows that all the meters have a lowest functional voltage below $50 \%$ of nominal voltage.

Table 2: Comparable test results

\begin{tabular}{|c|c|c|c|c|c|}
\hline & $\mathrm{A} 1$ & $\mathrm{~B} 1$ & $\mathrm{~B} 2$ & $\mathrm{C} 1$ & $\mathrm{D} 1$ \\
\hline $\begin{array}{c}\text { Measurement acc. voltage } \\
\text { [\% of } \mathrm{U}_{\text {Nominal }} \text { ] }\end{array}$ & 0.43 & 0.30 & 0.10 & 0.50 & N/A \\
\hline $\begin{array}{c}\text { Lowest functional voltage } \\
{\left[\% \text { of } \mathrm{U}_{\text {Nominal }} \text { ] }\right.}\end{array}$ & $48^{2}$ & 34 & $14^{2}$ & 28 & 24 \\
\hline $\begin{array}{c}1 \\
\text { Resolution time stamp }\end{array}$ & $\begin{array}{c}1 \\
\mathrm{sec}\end{array}$ & $\begin{array}{c}1 \\
\mathrm{sec}\end{array}$ & $\begin{array}{c}1 \\
\mathrm{~min}\end{array}$ & $\begin{array}{c}1 \\
\mathrm{sec}\end{array}$ \\
\hline Duration of event reported & Yes & No & Yes & No & Yes \\
\hline Minimum voltage reported & Yes & No & No & No & No \\
\hline
\end{tabular}

It should be noted that the meters $\mathrm{A} 1, \mathrm{~B} 1$, and $\mathrm{B} 2$ have the possibility to allow user defined events for undervoltages with a longer duration than the minimum duration indicated in the figures (blue area). This can allow for specification of events to be more in accordance with the requirements for supply voltage variations as defined in EN50160. However, as mentioned, the voltage must be below the specified threshold during the entire interval in order to be

2 - Time dependent 
registered as an event. The latter is not in accordance with EN50160.

\section{Conclusion}

The performed tests show that all the tested energy meters measure parameters relevant for power quality analysis. However, the tests also show that there are significant differences. The implementation of both continuous voltage measurements and event registration varies greatly between the tested meters and for most of them no common power quality standard (i.e. EN 50160, IEC 6100-4-30 or the Norwegian PQ Code [8]) seems to have been used as a basis. There is for example only one of the meters that have been tested who reports average values for voltage.

All of the energy meters have a lowest functional voltage below $50 \%$ of $\mathrm{U}_{\text {Nominal }}$ and should thereby be able to cope with an interruption threshold of $50 \%$ of $\mathrm{U}_{\text {Nominal }}$ as suggested by the Norwegian regulator in [6]. However meters $\mathrm{B} 1$ and $\mathrm{C} 1$ do not fulfil the demand regarding time stamp resolution of minimum 1 second as specified in [6]. Whether or not the energy meters tested could be reprogrammed to handle an interruption threshold of 50 $\%$ is not investigated.

Documentation regarding continuous voltage measurement implementation and event registration is at best limited for the meters that are part of this work. In some cases the vendors have been able to provide additional information regarding the power quality measurement functionality.

The tested energy meters could provide benefits for utilities compared to traditional energy meters in terms of enhanced control over the electrical power system. However, as a tool for performing power quality analyses, these meters have at present limited use value.

These tests suggests that utilities that are considering to install energy meters with power quality capabilities should demand documentation of both functionality and testing of the considered equipment from the vendors.

\section{Acknowledgement}

The PQM project is sponsored by the Norwegian Research Council together with:

- The Norwegian Electricity Industry Association

- The Norwegian Water Resources and Energy Directorate

- $\quad$ Statnett (the Norwegian TSO)

- Statkraft (the largest generation company in Norway)

- Norsk Hydro (generation company, heavy industry)

- $\quad$ Powel (ICT company)

- Hafslund Nett

- Helgeland Kraftlag (DSO)

- $\quad$ Lyse Nett (DSO)

- $\quad$ Skagerak Nett (DSO)

- Istad Nett (DSO)

- $\quad$ NTE (DSO)

In addition the authors would like to thank the meter vendors for supplying the necessary equipment and their time and assistance during the tests.

\section{References}

[1] EN 50160 Voltage characteristics of electricity supplied by public distribution systems, CENELEC 2007

[2] IEC 6100-4-30 Ed.2 Electromagnetic compatibility (EMC) - Part 4-30: Testing and measurement techniques -Power quality measusrement methods

[3] Koponen P., Seesvuori R., Böstman R., "Adding power quality monitoring to a smart kWh meter", Power Engineering Journal, Vol.10 (4), pp. 159-163, 1996

[4] Sapru V., "Power Quality Meters - Next Generation", Frost \& Sullivan Market Insight, January 2007

[5] Koçyiğit F., Yanıkoğlu E., Yilmaz A.S., Bayrak M., "Effects of power quality on manufacturing costs in the txtile industry", Scientific Research and Essay, Vol.4 (10), pp. 1085-1099, October 2009

[6] Avanserte måle- og styringssystem (AMS), Forslag til endringer i forskrift 11. mars $1999 \mathrm{nr}$. 301. Tilleggshøring 2009, http://www.nve.no/no/nyhetsarkiv-/nyheter/utsettervedtak-om-innforing-av-ams-

[7] Bickel J., "Selecting the right power quality meter", EC\&M, September 2003

[8] Reg. No. 1557 of 30 November 2004: Regulations relating to the quality of supply in the Norwegian power system, Norwegian Water Resources and Energy Directorate 2004 